\title{
Development of a purification technology for treatment of medium- and low-activity radioactive waste of radiochemical production from Co-60 and Cs-137
}

\author{
Gleb Apalkov ${ }^{1,2,}$, , Alexander Dyachenko ${ }^{1}$, Andrey Zhabin ${ }^{2}$, Sergey Smirnov ${ }^{2}$ \\ ${ }^{1}$ Tomsk Polytechnic University, Tomsk, Russia \\ ${ }^{2}$ Mining and Chemical Combine, Zheleznogorsk, Russia
}

\begin{abstract}
The technological flowchart of purification of medium- and low-activity waste from Co-60 and Cs-137 is developed and introduced. The developed purification scheme has been successfully tested using genuine medium- and low-level liquid radioactive waste of radiochemical production containing complexing and colloid forming components (complexons, surfactants). The optimal conditions of the presented method of purification ensure reduction of the residual specific activity of $60 \mathrm{Co}$ and $137 \mathrm{Cs}$ radionuclides in the solution to less than $0,9 \mathrm{~Bq}$ per litre.
\end{abstract}

\section{Introduction}

A critical task for providing radiation safety at radiochemical plants is solution to the problem of treatment and reprocessing of liquid radioactive waste (LRW), generated from the operation of power installations, various technological procedures with solutions containing radionuclides, during decontamination of equipment, etc. Liquid radioactive wastes are collections of wastes from drains collectors and vacuum drainage of floor, decantates from clarifiers, liquid wastes from specialized laundries. In case of considerable volumes of LRW not only decontamination factor (index), but also residue levels of radionuclides in solutions after their treatment are critical, that enables reuse of water resources without boiling and utilization of stillage residue. The main radionuclides which LRW are purified from are $137 \mathrm{Cs}, 60 \mathrm{Co}$. Ion-selective methods of purification from $60 \mathrm{Co}$ used in the technology suggests preliminary acid treatment of solutions aimed at destroying complexing agents and subsequent stages of radionuclide release, e.g., use of inorganic sorbent agents and cation exchange resins used for desalinization. The employed methods ensure efficient decontamination from $137 \mathrm{Cs}$ with decontamination factor of $102 \div 104$. However, the decontamination factor for $60 \mathrm{Co}$ is usually less than 102 , which does not allow reducing general activity of solutions after treatment of less than $10 \div 50 \mathrm{~Bq} / \mathrm{L}$.

The process solutions of LRW, generally, contain not only such components fed into solutions as aminopolycarboxylic acids; ethane diacid, citric acid, tartaric acid and their salts; sodium salts of ethylenediaminotetraacetic (EDTA) and diethylene triamine pentaacetic acids (DTPA), but also organic components with variable composition, formed as a result of radiolysis on long storage of LRW which form with $60 \mathrm{Co}$ complex chelated compounds with high stability constants $[1,2]$. Therefore, a prerequisite for increasing decontamination factor for $60 \mathrm{Co}$ is total destruction (oxidation) of all organic components of LRW regardless of their composition. Surfactants contained in the solutions (anionic, ampholytic, and nonionic SAS), high-molecular compounds, biocolloids also require both techniques intensifying oxidation decomposition and methods for special destruction of a colloid, containing 60Co.

Well-known methods of extracting the radionuclide 60Co from LRW at nuclear power plants are introducing Fe (III) and $\mathrm{Ni}$ (II) cations into LRW upon contact with potassium ferricyanide with molecular ratio from 2:1 to 4:1, allowing the solution to stand at room temperature and centrifugal separation of residue [3]. However, since there is no stage of oxidation of organic components of LRW, reagent consumption and sludge formation increase. Moreover, the technological adaptation of these methods requires expensive equipment, necessary for removing fine-grained sludge - a cascade of filtering centrifuges with the separation factor not less than 15000 .

Treatment of LRW generated at nuclear power stations involves their preliminary vaporization resulting in formation of condensate and stillage residue, ozonation of stillage residue, removal of radioactive slurry and concentrating the filtrate by deep evaporation $[4,5]$. The main drawbacks of this method are: insufficiently effectiveness of a special stage

\footnotetext{
${ }^{*}$ Corresponding author: apalkov@tpu.ru
} 
of $60 \mathrm{Co}$ extraction from the solution after ozonation and, as a result, inefficient removal of $60 \mathrm{Co}$, that requires concentrating the filtrate by evaporation; high power consumption of the process; increased reagent consumption (ozone); need to keep constant $\mathrm{pH}$ level; as well as exclusive fire- and explosion safety requirements during the process. LRW stillage residue is also purified from radioactive cobalt and cesium by oxidation of stillage residue with hard ultra-violet rays (UF) and removal of corrosion products by filtration [6,7]. We must also note low efficiency and technological complexity of arranging LRW oxidation in dynamic regime, technological complexity of arranging LRW oxidation in the static regime due to the process time (over 6 hours), reduced efficiency of UV-lamp when the salt content is over 10 $\mathrm{g} / \mathrm{l}$ and increased turbidity leading to inefficient oxidative destruction of organic components of LRW and removal of radionuclides.

\section{Experimental}

The aim of the research is to develop a technologically applicable method for purification of medium- (MAW) and lowactivity waste (LAW) from ${ }^{60} \mathrm{Co}$ with simultaneous purification from ${ }^{137} \mathrm{Cs}$ at radiochemical plants. The task was to reduce remaining specific activity of MAW and LAW solutions in terms of ${ }^{137} \mathrm{Cs}$ and ${ }^{60} \mathrm{Co}$ content to the level, sufficient to classify LRW as non-radioactive waste according to the requirements of OSPORB-99/2010 [8] (allowing subsequent use of purified solutions).

A comprehensive approach aimed at increasing the decontamination index of medium- (MAW) and low-activity (LAW) LRW from ${ }^{60} \mathrm{Co},{ }^{137} \mathrm{Cs}$ and ensuring the required level of radionuclides removal involves catalytic oxidation of organic components of LRW and coagulative and precipitative extraction of radionuclides with mixed ferricyanides of transition metals followed by subsequent treatment of filtrate with cation exchange resin. The technological flow-chart of the developed method of purification is given in figure 1. The critical factor is the adequacy of destruction of complexing and colloid forming (organic) agents of LRW.

As stock solution for purification genuine slurry decantates after precipitation of drainage and desorbing solutions, formed after decontamination of production equipment at the spent fuel storehouse WWER-1000 and equipment in the independent spent-fuel storage installation room RBMK-1000 were used. The composition of stock solution (used during the research) is given in Table 1.

Table 1. Chemical and radionuclide composition of stock solution.

\begin{tabular}{|l|c|c|}
\hline \multicolumn{1}{|c|}{ Component or criteria } & Dimension & Value \\
\hline Total salt content & $\mathrm{g} / 1$ & $20 \div 70$ \\
\hline Oxalate-ion & $\mathrm{g} / 1$ & 2 \\
\hline Carbonate-ion & $\mathrm{g} / 1$ & 2 \\
\hline EDTA & $\mathrm{mg} / 1$ & $0 \div 100$ \\
\hline ASs (anionic surfactants) & $\mathrm{mg} / 1$ & $8,5 \div 50$ \\
\hline $\mathrm{pH}$ & & $\mathrm{up}$ to $4,56 \times 10^{4}$ \\
\hline $\mathrm{Cs}^{137}$ & $\mathrm{~Bq} / \mathrm{L}$ & up to $1,02 \times 10^{3}$ \\
\hline $\mathrm{Co}^{60}$ & $\mathrm{~Bq} / \mathrm{L}$ & \\
\hline
\end{tabular}

Well-known catalysts for oxidation destruction of organic compounds in nitric acid media are platinum catalysts, applied to anion exchange resins (VP-1AP and other), silica gels, carbons, etc. [9-11]. Despite the advantages of heterogeneous catalytic processes, their industrial application in radiochemical technology is limited, firstly, due to the high cost of the (platinum) catalyst and non-recoverable losses of a platinum-group metal in the course of operation. As solid state catalyst of oxidation destruction of organic components of LRW in nitric acid media we use: platinum catalyst (Pt/VP-1AP), applied to anion exchange resin VP-1AP (GOST 20301-74) with platinum weight content of up to 2\%, and two new types of solid state catalysts developed by the authors - nickel-ferricyanide catalyst [12] on VP-1AP carrier and bimetal platinum-zirconia catalysts (carriers - silica gel, aluminum oxide) [13].

Characteristics of the prepared solid state catalysts used during the process are given in Table 2. Total surface area of catalysts is determined using the method of thermal desorption of nitrogen. Chemical activation of the obtained catalysts is carried out in the dynamic regime with $20 \div 55$ column volumes of $1,5 \mathrm{~mol} / \mathrm{L}$ solution of nitric acid at the speed of $7 \div 12$ column volume per hour. 


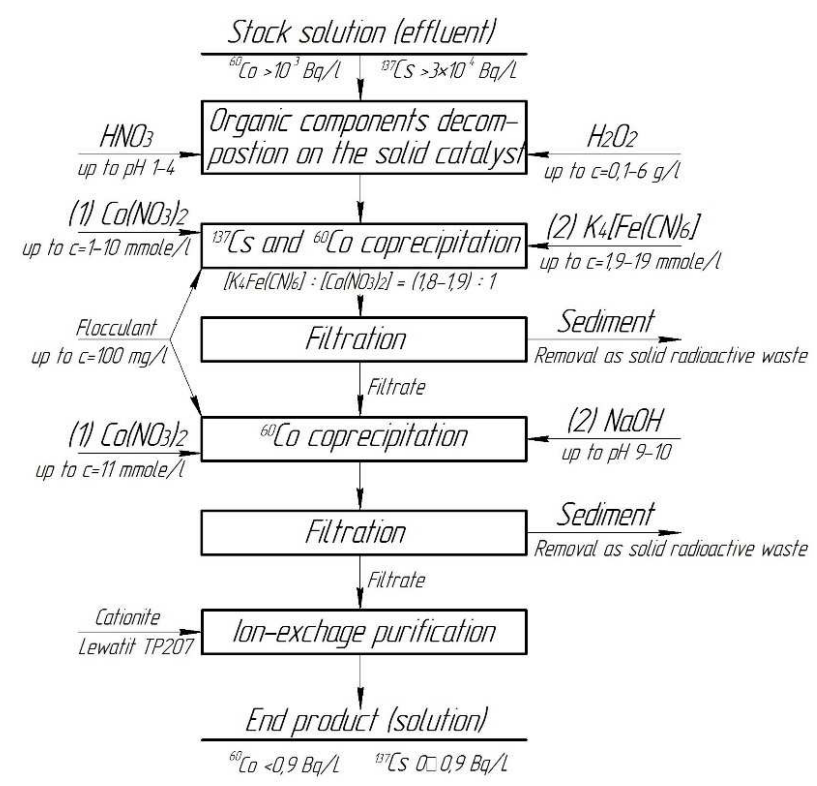

Fig. 1. Flowchart of purification of medium- and low-activity waste from ${ }^{137} \mathrm{Cs}$ and ${ }^{60} \mathrm{Co}$.

Table 2. Characteristics of the catalysts used during the research.

\begin{tabular}{|l|l|c|c|c|}
\hline \multicolumn{1}{|c|}{ Catalyst } & \multicolumn{1}{|c|}{ Catalyst carrier } & Pt, \% & $\begin{array}{c}\text { Particle size } \\
\text { distribution, } \mathrm{mm}\end{array}$ & Surface area, $\mathrm{m}^{2} / \mathrm{g}$ \\
\hline $\mathrm{Pt} / \mathrm{VP}-1 \mathrm{AP}$ & Anion exchange resin & 1,97 & $0,3 \div 0,5$ & 18,47 \\
\hline $\mathrm{Pt} / \mathrm{Zr} / \mathrm{SiO}_{2}\left(\mathrm{Al}_{2} \mathrm{O}_{3}\right)$ & Silica gel $($ Aluminum oxide) & 0,08 & $0,25 \div 0,35$ & $70,31(10,47)$ \\
\hline $\mathrm{R}-\mathrm{Ni}\left[\mathrm{Fe}(\mathrm{CN})_{6}\right]$ & Anion exchange resin & - & $0,3 \div 0,5$ & 18,36 \\
\hline
\end{tabular}

Testing of regimes and optimization of the developed method of purification of MAW and LAW from radionuclides ${ }^{60} \mathrm{Co}$ and ${ }^{137} \mathrm{Cs}$ is assessed on the results of experiments (research) on the laboratory installation given in Fig. 2.

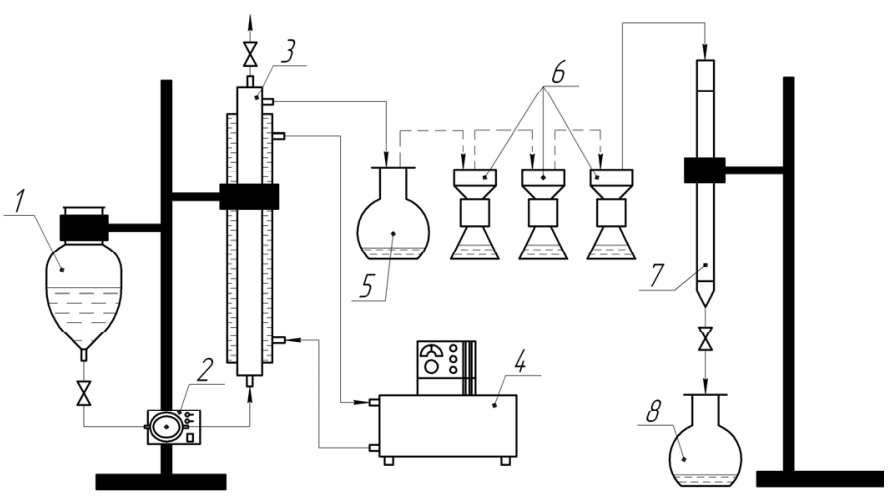

Fig. 2. Laboratory installation diagram of LRW purification from ${ }^{60} \mathrm{Co}$ and ${ }^{137} \mathrm{Cs}$.

Laboratory installation includes: a stock bottle with stock solution (1), a peristaltic pump (2), a catalytic oxidation column (3), a thermostat (4), a stock bottle for receiving solution from the catalytic column (5), receiving filters with removable fluoroplastic cartridges (6), an ion-exchange column (7), a receiver stock bottle for purified solution (8).

LRW is purified in the following sequence: the LRW solution to be treated, regardless of its conditions, is corrected with hydrogen nitrate up to $\mathrm{pH} 1 \div 4$. Next, hydrogen peroxide is added to reach concentration of hydrogen peroxide in the solution of up to $0,1-3,3 \mathrm{~g} / \mathrm{L}$. The corrected solution passes through the first stage of LRW purification in the catalytic oxidation column, operating at $47,5 \div 80^{\circ} \mathrm{C}$, having the flow speed of $3 \div 15$ column volume/per hour, that ensures contact time of the solution with the catalyst in the interval of $50 \div 130 \mathrm{sec}$. 
The developed method and catalytic oxidation mode ensure 99,85-99,91\% of decomposition of organic components of LRW (EDTA, oxalate-ion, ASs), which can be achieved when using the indicated types of solid state catalysts, given in Table 2, and depends on the concentration of an organic component in the stock solution. The residual value of organic components does not exceed $100 \mu \mathrm{g} / \mathrm{l}$.

The laboratory catalytic column is a device made from quartz glass with bottom feed of solution, a laminar flow zone, a catalysis zone, a gas separation zone. The catalysis zone is divided by meshed partitions. The prepared catalyst is loaded through the upper gate and squeezed by the upper meshed partition. In this case, the pore volume of the catalyst granular bed is $5,1 \div 12,5 \%$ of the bulk volume. The catalyst zone is a vertical cylindrical column filled with catalyst with «diameter/height» ratio of $1: 3 \div 1: 15$. The catalyst is a uniformly graded inorganic porous carrier, silica gel or anion exchange resin with the grain size of $0,25 \div 0,50 \mathrm{~mm}$, an active surface area of $18 \div 71 \mathrm{~m}^{2} / \mathrm{g}$ with a layer of ultrafine homogeneous chemically inactive in weak solutions of nitric acid metal (salt) composition with ratio to the carrier of 0,08-7,5\% mass, which are both oxidation catalysts of organic components of LRW and decomposition catalysts of hydrogen peroxide followed by formation of a hydroxyl radical.

The solution which has gone through the phase of catalytic oxidative destruction proceeds to the second stage flocculation and precipitation. At the first operation a transition metal nitrate $(\mathrm{Co}, \mathrm{Ni}, \mathrm{Zn})$ is added to the solution up to a concentration of 1,0-12,6 mmol/L. Then, while stirring intensively for $15 \div 20$ minutes, solution of Besfloc K-051C flocculant is added up to a concentration of 10-100 mg/l, followed by addition of solution of an alkali metal ferricyanide up to a concentration of 1,9-19,0 $\mathrm{mmol} / \mathrm{L}$. In this case, the molecular ration between a transition metal nitrate $(\mathrm{Co}, \mathrm{Ni}$, $\mathrm{Zn}$ ) and an alkali metal ferricyanide is from 1,0:1,5 to 1,0:1,9. Upon the total sedimentation of residue after $0,5 \div 2,2$ hours the clarified part is decantated, i.e. intermediate filtration is carried out at the speed of $5,0-15,0 \mathrm{~mL} / \mathrm{min} \cdot \mathrm{cm}{ }^{2} \mathrm{through}$ MFFK-3G membrane $(0.45 \mu \mathrm{m}$ pore size), MFFK-4G $(0,65 \mu \mathrm{m}$ pore size) or TRUMEM membrane with $0,45-0,60 \mu \mathrm{m}$ pore size. Dense precipitate from the reactor bottom is deposited on the removable cartridge of the receiving filter and filtrated at the speed of $0,2 \div 7,0 \mathrm{~mL} / \mathrm{min} \cdot \mathrm{cm}^{2}$ through MFFK-1G membrane $(0,15 \mu \mathrm{m}$ pore size $), \mathrm{MFFK}-2 \mathrm{G}(0,25 \mu \mathrm{m}$ pore size) or TRUMEM membrane with $0,15 \div 0,25 \mu \mathrm{m}$ pore size. Decantate and filtrate are combined and proceed to the next operation of the flocculation and precipitation stage.

Here, Besfloc K-051C flocculate is added, while being stirred intensively, to the solution which has a residual concentration of alkali metal ferricyanide of $0,9-6,4 \mathrm{mmol} / \mathrm{L}$ up to a concentration of $10-100 \mathrm{mg} / \mathrm{l}$. Then, diethyldithiocarbamate of an alkali metal is added up to a concentration of 10-100 mg/l. Further, the solution is mixed during $10 \div 15$ minutes and a transition metal nitrate $(\mathrm{Co}, \mathrm{Ni}, \mathrm{Zn})$ is added up to a concentration of $1,8-12,8 \mathrm{mmol} / \mathrm{L}$. It ensures excess of a transition metal nitrate $(\mathrm{Co}, \mathrm{Ni}, \mathrm{Zn})$ as compared to ferricyanide. At the second operation precipitate detachment is similar to one at the first operation. The obtained decantate and filtrate are combined and proceed to the third operation of the flocculation and precipitation stage.

Then, Besfloc K-4000 flocculate is added, while being stirred intensively, to the solution up to a concentration of 10$100 \mathrm{mg} / \mathrm{l}$, followed by addition of sodium hydrate solution up to $\mathrm{pH} 9-10$. At the third operation precipitate detachment is similar to one at the first operation. The second and the third operations can be combined without intermediate detachment of sediment. All three operations can also run subsequently in one device if to use an intermediate container for filtrates and decantates.

Final purification from ${ }^{60} \mathrm{Co}$ is carried out with cation exchange resin, selective to ions of transition and heavy metals, e.g., Lewatit MonoPlus TP 207, which is a weakly basic macroporous cation exchange resin with chelate groups of iminodiacetic acid. The solution passes through the ion-exchange column at the speed of $4 \div 10$ column volume/per hour, with «diameter/height» ratio of the filling layer geometry of $1: 10 \div 1: 20$. The third stage - ion-exchanging - can be excluded, in case the salt content of filtrate after coagulation and precipitation stage does not exceed $10 \mathrm{~g} / \mathrm{l}$.

\section{Results and discussion}

The developed method has significant advantages over the known (indicated earlier [3]-[7]) methods of purification of LRW generated at radiochemical plants and nuclear power stations due to a more complete oxidation of organic components of LRW in the dynamic mode of the column operation during considerably less time available for contact $(50 \div 130 \mathrm{sec})$ combined with high efficiency of the column $(3 \div 15$ column volume/per hour), at lower temperature of the process $\left(47,5 \div 80^{\circ} \mathrm{C}\right)$. A column with the filling layer of a catalyst and a dynamic mode of oxidation decomposition stage condition simple hardware arrangement of the process. Process variables do not depend on turbidity and salt composition of the solution and allow a wide range of the flow rate and temperature setting without sacrificing oxidation efficiency of organic components of LRW, which enables treatment of cloudy solutions (e.g., decantates) without preliminary clarification. Process variables (contact time, efficiency) can be easily changed in terms of both increase/decrease of the height of the catalyst filling layer and flow rate. Application of a catalytic mechanism of oxidation decomposition allows significantly reducing the amount of hydrogen peroxide added to LRW up to $3 \%$ volume (unlike UV-treatment of stillage residue) at the oxidation stage. Oxidation decomposition is carried out in acidic medium at $\mathrm{pH} 1 \div 4$, which allows taking an advantage of synergism resulting from addition of low concentration of the second oxidizing agent - hydrogen nitrate during catalyst oxidation. The solution is mixed in the contact zone due to intensive spontaneous gas release in the pore space of the catalyst filling layer that increases the flow turbulence and decreases the contact time. The suggested method 
excludes sludge formation and precipitation of products of oxidation decomposition at the stage of oxidation decomposition. Thus, extraction of solid phase prior to coagulation and precipitation can be neglected.

An alkali metal diethyldithiocarbamate is added at the second operation of the coagulation and precipitation stage (when the base quantity of ${ }^{60} \mathrm{Co}(65,1 \div 95,4 \%)$ has already precipitated with mixed ferricyanides). It is added into dilute acidic solution ( $\mathrm{pH} 1 \div 4$ ), containing ferricyanide of an alkali metal and flocculant, which ensures precipitation of ${ }^{60} \mathrm{Co}$ in ion form (the most suitable for fixation of cobalt with diethyldithiocarbamate). The sequence of addition of an alkali metal diethyldithiocarbamate allows, unlike the method described in [4], initial binding of radioactive cobalt with diethyldithiocarbamate (resulting in formation of finely dispersed flocculated cloud, detected by turbidity change of the LRW solution). After 10-15 minutes of contact a transition metal nitrate ( $\mathrm{Co}, \mathrm{Ni}, \mathrm{Zn}$ ) can be added followed by cooprecipitation of ${ }^{60} \mathrm{Co}$, remaining in the solution, both with residue of a transition metal diethyldithiocarbamate (Co, $\mathrm{Ni}, \mathrm{Zn}$ ) and with residue of a transition metal ferricyanide (Co, Ni, Zn). Since an excessive amount of transition metal nitrate $(\mathrm{Co}, \mathrm{Ni}, \mathrm{Zn})$ is used, the whole diethyldithiocarbamate is removed from the LRW solution with a precipitate, without polluting LRW with the added organic components. In case of simultaneous coprecipitation of diethyldithiocarbamate of a transition metal $(\mathrm{Co}, \mathrm{Ni}, \mathrm{Zn})$ and ferricyanide of a transition metal $(\mathrm{Co}, \mathrm{Ni}, \mathrm{Zn})$ dense precipitate is formed which is easily removed by microfiltration. The suggested method ensures reducing the amount of the introduced diethyldithiocarbamate of an alkali metal more than 100 times, when using it in concentration of 10-100 $\mathrm{mg} / \mathrm{l}$ (considerably lower as compared to [6]).

When analyzing the results of the experiments conducted on the laboratory installation and improvement of the method of LRW (MAW, LAW) purification from radionuclides, efficiency of the developed method was estimated. The data are given in Table 3.

Table 3. Estimate of efficiency of the developed method of purification from ${ }^{60} \mathrm{Co}$ and $\mathrm{Cs}^{137}$.

\begin{tabular}{|c|c|c|c|c|}
\hline \multirow[t]{2}{*}{ № of treatment stage } & \multicolumn{2}{|c|}{$\begin{array}{l}\text { Solution activity after } \\
\text { treatment, } \mathrm{Bq} / \mathrm{L}\end{array}$} & \multicolumn{2}{|c|}{ Decontamination index } \\
\hline & $\mathrm{Co}^{60}$ & $\mathrm{Cs}^{137}$ & $\mathrm{Co}^{60}$ & $\mathrm{Cs}^{137}$ \\
\hline 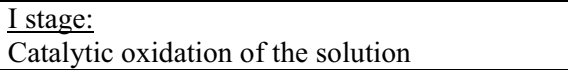 & $1,02 \times 10^{3}$ & $4,56 \times 10^{4}$ & - & - \\
\hline $\begin{array}{l}\text { II stage: } \\
\text { Coprecipitation of }{ }^{60} \mathrm{Co} \text { and }{ }^{137} \mathrm{Cs} \text { radionuclides } \\
\text { with mixed ferricyanides of transient metals } \\
(\mathrm{Co}, \mathrm{Ni}, \mathrm{Zn})\end{array}$ & 6 & 16 & 170 & 2850 \\
\hline $\begin{array}{lcc}\text { Coprecipitation of } & { }^{60} \mathrm{Co} \text { with } & \mathrm{Na}- \\
\text { diethyldithiocarbamate } & \text { mixed } & \text { with } \\
\text { ferricyanides of transient } & \text { metals }(\mathrm{Co}, \mathrm{Ni}, \mathrm{Zn})\end{array}$ & 3,5 & 5 & 1,72 & 3,20 \\
\hline $\begin{array}{l}\text { Coprecipitation of }{ }^{60} \mathrm{Co} \text { with hydroxides of } \\
\text { transient metals } \\
(\mathrm{Co}, \mathrm{Ni}, \mathrm{Zn})\end{array}$ & 2 & 3,6 & 1,75 & 1,39 \\
\hline $\begin{array}{l}\text { III stage: } \\
\text { Ion-exchange purification }\end{array}$ & $<0,9$ & $<0,9$ & $>2,20$ & $>4$ \\
\hline Result & & & $>1133$ & $>51667$ \\
\hline
\end{tabular}

Low decontamination indexes during after-purification stages are conditioned by low content of radionuclides in the solution (after the first operation of coprecipitation) versus content of an added stable transition metal. The aim of the final ion-exchanging purification in the developed scheme is a barrier protection from slip of removed cobalt-60 radionuclides. At this stage it is important not to ensure high decontamination indexes, but a stable maximum low content of both radionuclides in the flowing solution and added salts of transient metals.

After extracting ${ }^{60} \mathrm{Co}$ and ${ }^{137} \mathrm{Cs}$ radionuclides (with activity lower than $0,9 \mathrm{~Bq} / \mathrm{L}$ ), the solutions, according to [8], do not belong to radioactive waste and do not require any measures on reducing radioactivity which allows their later use for different technological operations.

As a result of a successful laboratory testing of the developed method a technological flowchart for purification of MAW and LAW from ${ }^{60} \mathrm{Co}$ and ${ }^{137} \mathrm{Cs}$ (see fig 3) was suggested. The installation includes: a stock bottle with stock solution of LRW (1), membrane pumps $(2,6,9,12,15)$, a catalytic oxidation column [14] (3), a thermostat (4), a stock bottle for receiving solution from the catalytic column (5), «mixer tank-settling tank» reactors (for every operation of coagulation and precipitation stage, and which have sedimentary residue zones and decantate removal zones) equipped with an agitator $(7,10,13)$, receiving filters with remotely-removable fluoroplastic cartridges $(8,11,14)$, ion-exchanging column $(16)$, control valves $(\mathrm{B} 01 \div \mathrm{B} 33)$. 


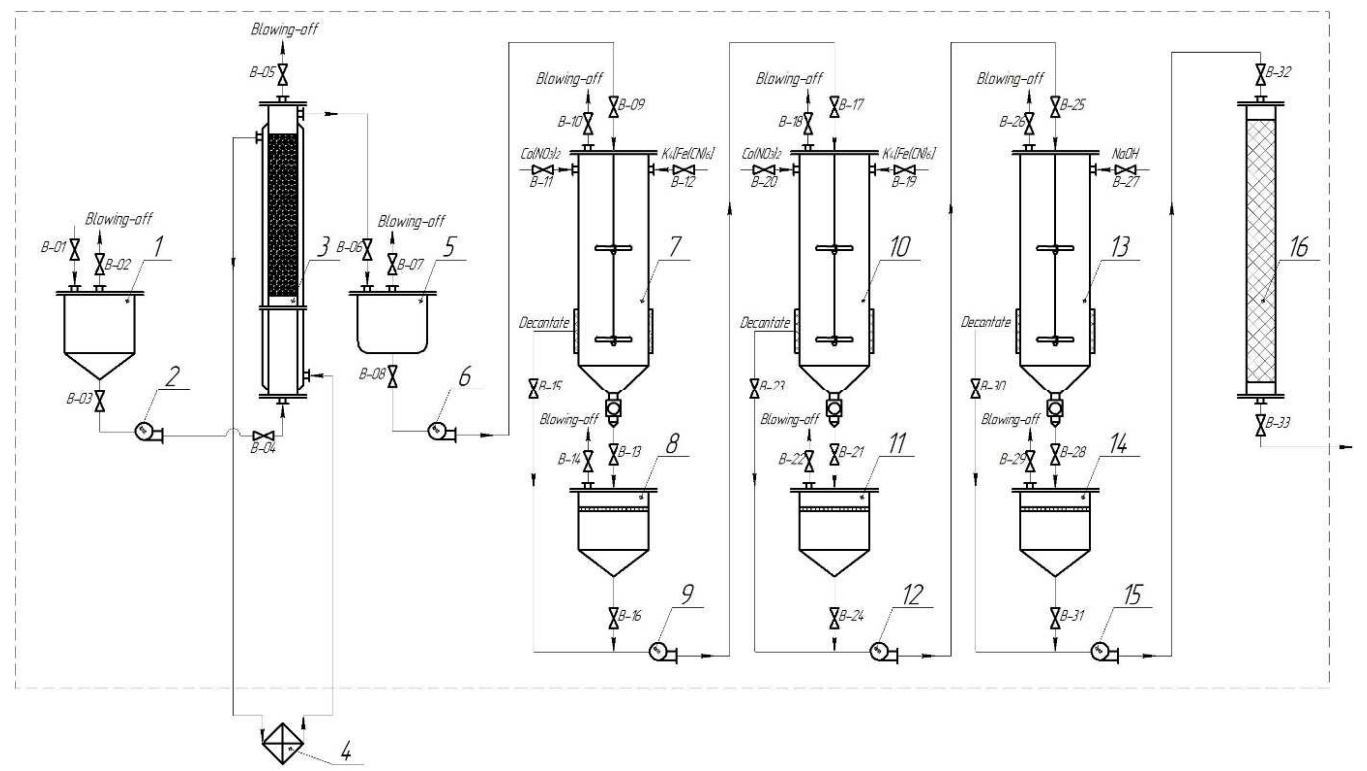

Fig. 3. Technological flowchart of the purification process of medium- and low-activity waste from ${ }^{60} \mathrm{Co}$ and ${ }^{137} \mathrm{Cs}$.

\section{Conclusions}

The developed process of LRW purification from ${ }^{60} \mathrm{Co}$ and ${ }^{137} \mathrm{Cs}$ has been successfully tested using real medium- and low-level liquid radioactive waste of radiochemical production containing complexing and colloid forming components (complexons, SAS).

The optimized parameters of the process of purification allowed reducing residual specific activity of ${ }^{60} \mathrm{Co}$ and ${ }^{137} \mathrm{Cs}$ in the solution up to less than $0,9 \mathrm{~Bq} / \mathrm{L}$.

A technological flowchart for purification of MAW and LAW from ${ }^{60} \mathrm{Co}$ and ${ }^{137} \mathrm{Cs}$ was developed and suggested for application.

The analysis of the results allows considering the developed method to be technologically applicable for treatment of decontamination fluids, drain water, wastes from specialized laundries at radiochemical enterprises, containing different concentrations of complexons and SAS.

\section{References}

1. Management of Low and Intermediate Level Radioactive Wastes with Regard to Their Chemical Toxicity 2002 IAEATECDOC-1325 IAEA: Vienna, Austria

2. Handling and Processing of Radioactive Waste from Nuclear Applications 2001 TRS No. 402 IAEA: Vienna, Austria

3. Kulyuhin S A, Konovalova N A, Gorbacheva M P 2013 Radiochemistry 2013 vol 55 № 1 pp 242-248

4. Seliverstov A F, Lagunova Yu O, Ershov B G, Gelis V M, Basiev A G 2009 Radiochemistry vol 51 № 3 pp 326-328

5. Kudryavcev B K, e.a. Patent RF 2004 № 2226726

6. Shmakov L V, e.a. Patent RF 2012 № 2467419

7. Seliverstov A F, Lagunova Yu O, Ershov B G, Morozov P A, Kamrukov A S, Shashkovskii S G 2008 Radiochemistry vol 50 № 1 pp 70-74

8. Main Sanitary Regulations to Ensure Radiation Safety (Osborn - 99/2010). SP 2.6.1.2612

9. Ananyev A V 2005 PhD dissertation Frumkin Institute of Physical Chemistry and Electrochemistry of Russian Academy of Sciences Moscow 391 p (in Russian)

10. Tyumentsev M S 2013 PhD dissertation Frumkin Institute of Physical Chemistry and Electrochemistry of Russian Academy of Sciences Moscow $173 \mathrm{p}$ (in Russian)

11. Shilov V P, Dzuybenko V I, Astafurova L N, Krot N N 1990 J. applied chemistry vol 2 pp 348-353

12. Apalkov G A 2014 IOP Conf. Ser.: Mater. Sci. Eng. vol 66012033

13. Zhabin A Yu, Apalkov G A, Smirnov S I Patent RF 2016 № 2598944

14. Apalkov G A, Zhabin A Yu, Smirnov S I Patent RF 2016 № 158504 